\title{
NUMERICAL STUDY FOR NEAR SHORE SUBMERGED BREAKWATERS
}

\author{
E.M. Heikal and A.S. Koraim \\ Water Eng. Dept., Faculty of Eng., Zagazig Univ., Zagazig, Egypt.
}

\begin{abstract}
The validity of linear wave theory in determining the efficiency of trapezoidal submerged breakwater located near shore is analyzed using the Eigenfunction expansion method. The transmission coefficient and the wave height distribution around the breakwater were calculated for different beach slopes, breakwater side slopes and incident wave field conditions. The validity of the numerical model is obtained by comparing the results with the experimental data. It is concluded that; the proposed numerical model is exactly valid for vertical or nearly vertical breakwaters for different wave properties and beach slopes. The numerical results are adjusted for different breakwater slopes with a correction factor.
\end{abstract}

INTRODUCTION:

The submerged breakwaters are successfully employed in a variety of low and moderate wave energy applications. This type of breakwaters minimizing the pollution aspects near shores in which permits to exchange the water mass by wave run up the breakwater crest. The linear wave theory is easy and efficient in determining the offshore structure efficiency to control the wave climate around the submerged breakwaters on horizontal beaches. The control of wave height near shores using the submerged breakwaters is required for decreasing the beach erosion and enables to use the protected coasts efficiently. The submerged breakwaters control the wave height by absorbing some of wave energy by maturely wave breaking due to wave reflection, wave diffraction and wave shoaling.

Theoretical and experimental studies have been carried out to study the efficiency of submerged breakwaters on wave transmission using different breakwater shapes located on horizontal or sloping beaches. This problem have been studied by Hall and Hall (1940), Dean (1945), Hamilton (1950), Jolnnson, Fuches and Morison (1951), Dick and Brebner (1968), Abdul Khader and Rai (1980) and Heikal (1997) have studied this problem. Most information about wave transmission, reflection and energy dissipation around trapezoidal submerged breakwater was obtained from hydraulic model tests as summarized in Shore Protection Manual (SPM) and the report of Seeling (1980). Kobayashi and Wurjanto (1989) modified the numerical model developed by Kobayashi et al. (1987) and Kobayashi and Watson (1987) for predicting the uprush and downrush of normally incident. monochromatic waves on rough or smooth impermeable slopes. Abul-Azm (1993) and Heikal (1997) solve the 
linear wave potential using the Eigenfunction expansion to determine the thin vertical submerged breakwater efficiency

The effect of beach slope, wave properties and the breakwater side slope on the wave field behind trapezoidal submerged breakwaters require many researches to determine the wave field around this type of structures and how the shore processes are affected accordingly. In the present study, the wave field was studied along the sloping beach around the trapezoidal submerged breakwater. The breakwater was modeled as a trapezoidal submerged impermeable barrier supported on an impermeable sloping or horizontal bed. Herein, the comparison between the theoretical results using the Eigenfunction expansion method and the experimental results for near-shore trapezoidal submerged breakwater was made. Different wave frequencies, relative submergency, breakwater side slopes and beach slopes were taken into considerations for intermediate and shallow water depths.

\section{THEORETICAL ANALYSIS:}

The analysis will proceed under the assumptions that the fluid is incompressible and invisced and the motion is irrotational. Further assumption is that the boundary conditions on the free surface can be linearized. The breakwater model is considered as impermeable trapezoidal wall submerged down the undisturbed water-depth. The relative wave height at any location around the breakwater model is described as follows:

$$
\begin{aligned}
\frac{H}{\mathrm{H}_{\mathrm{i}}} & =\frac{\partial \phi_{1}}{\partial t} / \frac{\partial \phi_{1}}{\partial t} \quad \mathrm{x}<0 \\
& =\frac{\partial \phi_{2}}{\partial t} / \frac{\partial \phi_{\mathrm{I}}}{\partial t} \quad x>0
\end{aligned}
$$

where $\mathrm{H}$ is the generated wave height at any location in the presence of breakwater the and $\mathrm{Hi}$ is the incident wave height at the same location of $\mathrm{H}$ without the breakwater, the incident potential can be expressed as follows :

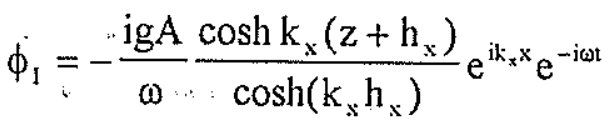

Where $A$ is the wave amplitude, $g$ is the acceleration of gravity, $\mathrm{k}$ is the wave number at any $x$ value $(k x=2 \pi /$ $\mathrm{Lx}), \mathrm{Lx}$ is the wave length at any $\mathrm{x}$ value, $\omega$ is the angular frequency $(\omega=2 \pi / \mathrm{T})$, and $\mathrm{T}$ is the wave period and $i$ is $\sqrt{-1}$.

The flow potential at the two flow regions can be expressed as follows: 


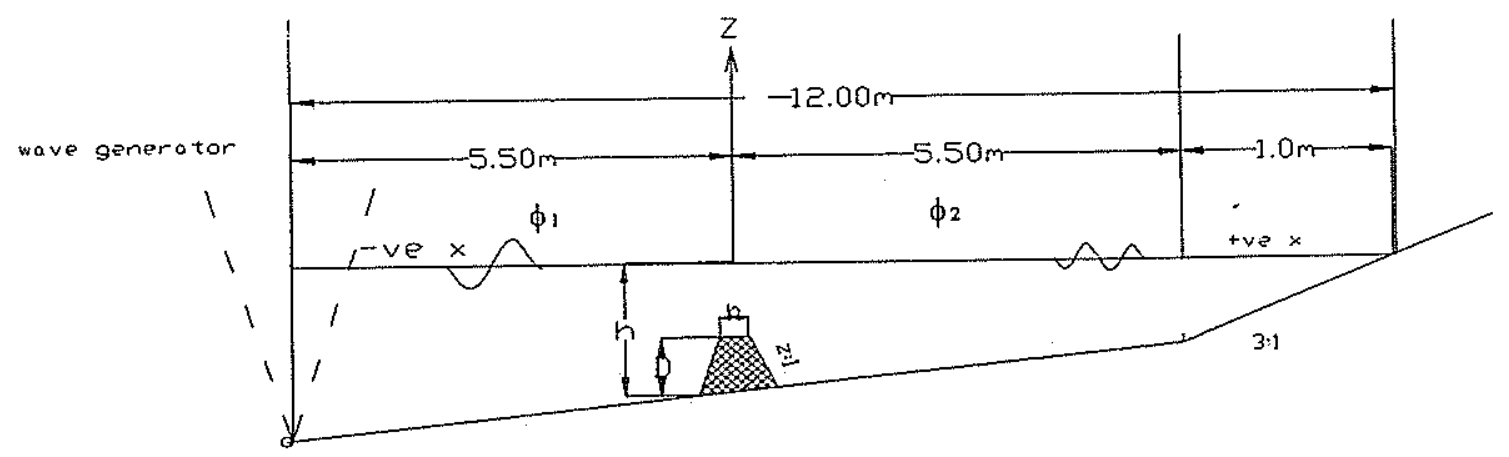

Figure. (1) Schematic Diagram for the Wave Flume

$\phi_{1}(\mathrm{x}, \mathrm{z})=\phi_{1}+$

$\sum_{n=0}^{\infty} A_{n}\left(\frac{-i g A}{\omega \cosh \left(k_{x} h_{x}\right)}\right)^{*} k_{n x}\left(z+h_{x}\right) e^{k_{n x} x}$

$\phi_{2}(\mathrm{x}, \mathrm{z})=\phi_{1}-$

$\sum_{n=0}^{\infty} A_{n}\left(\frac{-i g A}{\omega \cosh \left(k_{x} h_{x}\right)}\right)^{*}$
$\cos k_{n x}\left(z+h_{x}\right) e^{-k_{n x} x}$

$\mathrm{h}$ is the water depth., $A_{n}$ are complex coefficients to be determined. $k_{x}, k_{n x}$ are the solution of the dispersion relation :

$$
\omega^{2}=-g k_{n x} \tan \left(k_{n x} h_{x}\right) .
$$

Matching the potentials and velocities at $\mathrm{x}=0$ as follows:

1. $\phi_{1}(x, z)=\phi_{2}(x, z)$ at $x=0, z>-d$

i.e

$$
\sum_{n=0}^{\infty} A_{n} \cos k_{n x}\left(z+h_{x}\right)=0
$$

2. $\begin{aligned} & \partial \phi_{1} / \partial x= \\ & \partial \phi_{2} / \partial x=0\end{aligned}$ at $x=0, z<-d$
i.e

$$
\sum_{n=0}^{\infty} A_{n} A_{x} \cos k_{n x}\left(z+h_{x}\right) \mu_{n}+
$$

Where, $\mu_{0}=-\mathrm{ik}_{\mathrm{x}} \mathrm{D}$ for $\mathrm{n}=0$ and $\mu_{n}=k_{n x}$ D for $n>0$.

Equations (7), (9) can be solved for the values of the coefficients $A_{n}$. These two relations specify the potential along the z-axis. This condition is;

$$
\begin{aligned}
& G(z)=\sum_{n=0}^{\infty} A_{n} \cos k_{n x}\left(z+h_{x}\right) \\
& \text { at } x=0 \text { and } z>-d \\
& =\sum_{n=0}^{\infty} A_{n} \cos k_{n x}\left(z+h_{x}\right) \mu_{n}+i k_{x}\left(z+h_{x}\right) \\
& \text { at } x=0 \text { and } z<-d
\end{aligned}
$$

To determine the $A_{n}$ coefficients, the least square technique may be used, (Dalrymple and Martin 1990), which requires that the value;

$\int_{-h}^{0}|G(z)|^{2} \mathrm{dz}=0$ to be minimum

Minimizing this integral with respect to each of the $A_{n}$ leads to: 
Where $G^{*}(z)$ is the complex conjugate of $\mathrm{G}(\mathrm{z})$. Then by substitution;

$\sum_{n=0}^{N} A_{n}^{*}\left[S_{n m}+B_{n m} \mu_{n}^{*} \mu_{m}\right]=$

$i k_{s} D \mu_{m} B_{n m}$

Where;

$\mathrm{S}_{\mathrm{nm}}=\int_{-\mathrm{d}}^{0} \cos \mathrm{cos}_{\mathrm{mx}}\left(\mathrm{z}+\mathrm{h}_{\mathrm{x}}\right)^{*}$

$B_{n m}=\int_{-h}^{-d} \cos k_{n x}\left(z+h_{x}\right)^{*}$

\section{NUMERICAL RESULTS AND VERIFICATION:}

Experimental work was carried out to verify the validity of linear wave theory to predict the wave field around the trapezoidal submerged breakwaters of different side slopes near-shore. The results present the comparison between numerical and experimental results for the transmission coefficient and the wave field for different wave properties, beach slopes and breakwater side slopes.

Experiments were carried out in a tilting wave flume having Perspex sidewalls. The working section is 12 $\mathrm{m}$ long, $0.45 \mathrm{~m}$ deep and $0.30 \mathrm{~m}$ wide. A variable speed flap type wave generator was used to predict waves. Waves have a period range of 0.68 to 2.50 second and the stroke distance is $22 \mathrm{~cm}$. five different breakwater models of height $0.15 \mathrm{~m}, 0.075 \mathrm{~m}$ width of crest and side slopes of $0: 1$,
$0.5: 1,1: 1,1.5: 1$ and $2: 1$. The water depth ranged from 0.15 to $0.25 \mathrm{~m}$ and the bed slopes are $0.0 \%, 1.0 \%, 1.5 \%$ and $2.0 \%$. The details of experiments are mentioned in Heikal, et.al (2002)

Figure (2) presents the comparison between the transmission coefficient experimentally and numerically with the relative wave frequency $\left(\omega^{2} \mathrm{~h} / \mathrm{g}\right)$ for different beach slopes when $\mathrm{D} / \mathrm{h}=0.86$ and the breakwater side slopes are $0: 1,0.5: 1$, $1: 1,1.5: 1$ and $2: 1$ respectively. The numerical transmission coefficient coincides with the experimental results for vertical or nearly vertical breakwater. This means, that the experimental results obtained from the breakwater of side slopes of 0:1 and $0.5: 1$ give a good agreement with the numerical results.

The comparison between the relative wave heights calculated experimentally and numerically for different breakwater side slopes and beach slopes of $s=0 \%, 1 \%$ and $2 \%$ for $\mathrm{D} / \mathrm{h}=0.75$ and $\omega^{2} \mathrm{l} / \mathrm{g}=0.29,0.61$ and 1.74 are shown in figures (3)-(5) respectively. The numerical and experimental generated wave field seaside is irregular and has maxima and minima at periodical locations. Figures (3) and (5) show that the predicted relative wave height is nearly estimated for long and short waves $\left(\omega^{2} \mathrm{~h} / \mathrm{g} \quad=0.29\right.$ and 1.74) especially for the steepest side slopes $(0: 1$ and $0.5: 1)$ of different beach slopes. The predicted relative wave height is over estimation for 


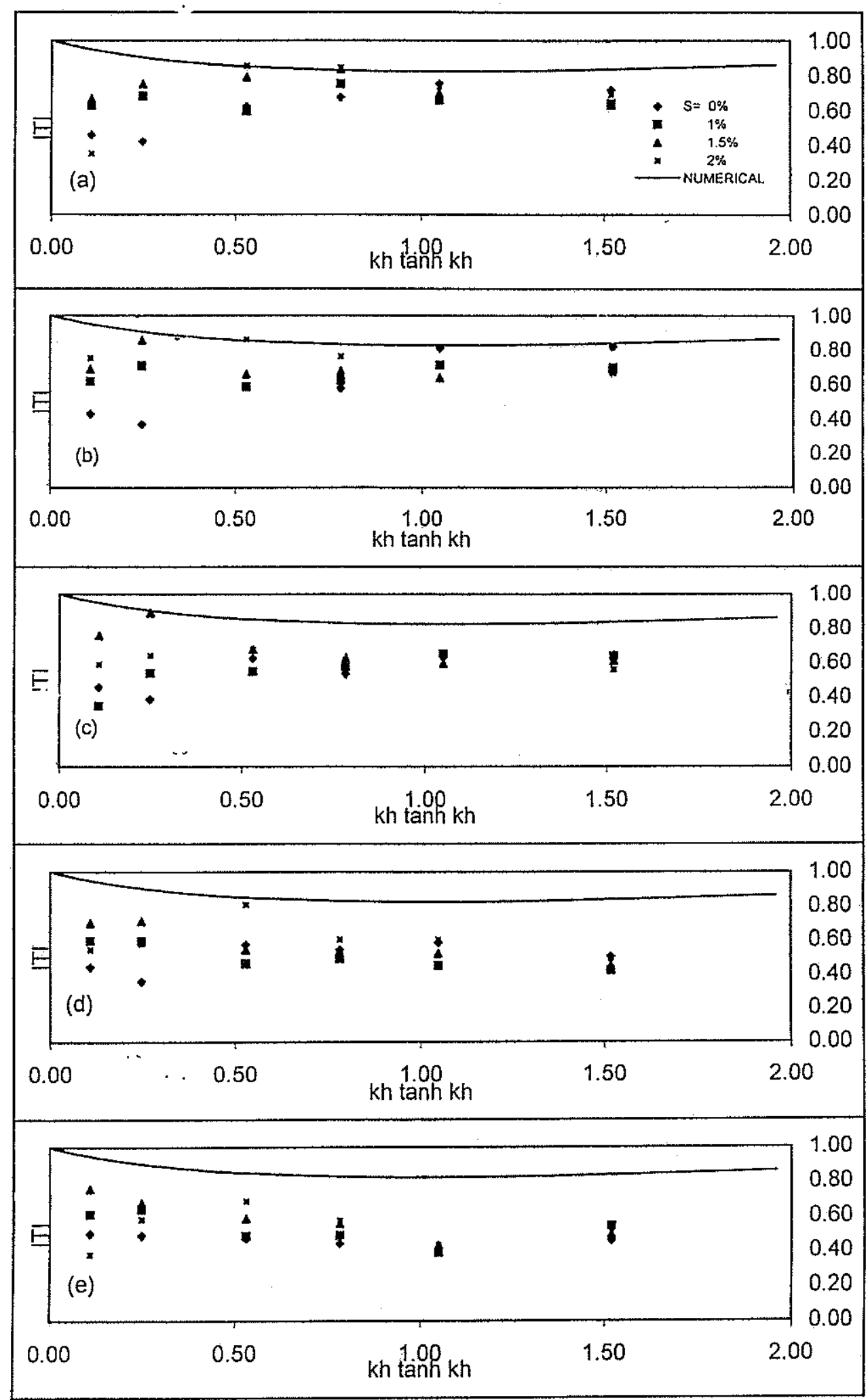

Fig. (2) The Comparison Between the Numerical and the Experimental Results for Transmission Coefficient and the Relative Wave Frequency When $D / h=0.86$ :
(a) $z: 1=0: 1$
(c) $z: 1=1: 1$
(b) $z: 1=0.5: 1$
(e) $z: 1=2: 1$
(d) $z: 1=1.5: 1$ 


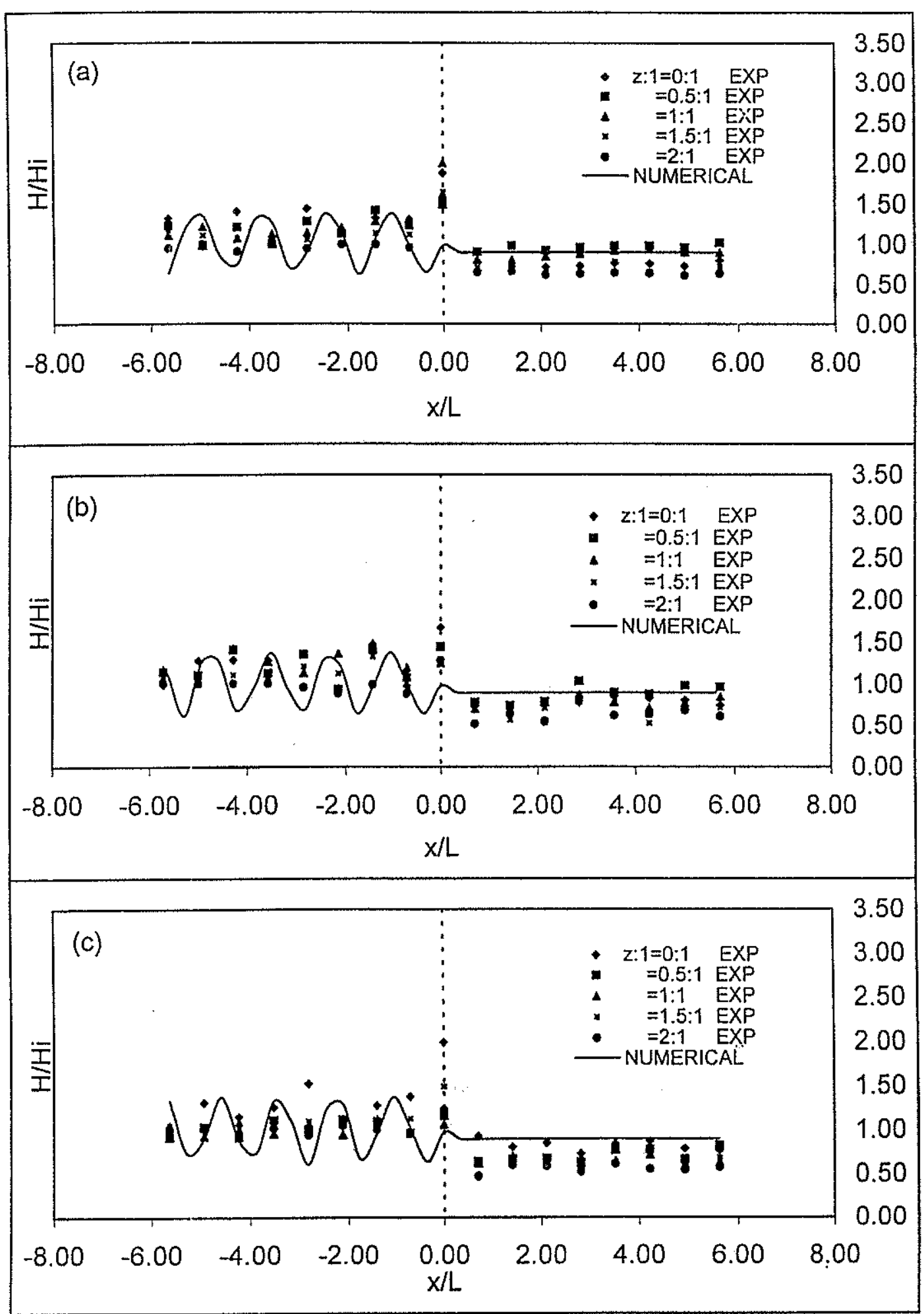

Fig. (3) The Comparison Between Numerical and Experimental Results for the Effect of the Breakwater Side Slope and the Relative Wave Height Distribution When kh tanh $(k h)=1.74$ And $D / h=0.75$ For:
(a) $\mathrm{s}=0 \%$
(b) $s=1 \%$
(c) $s=2 \%$ 


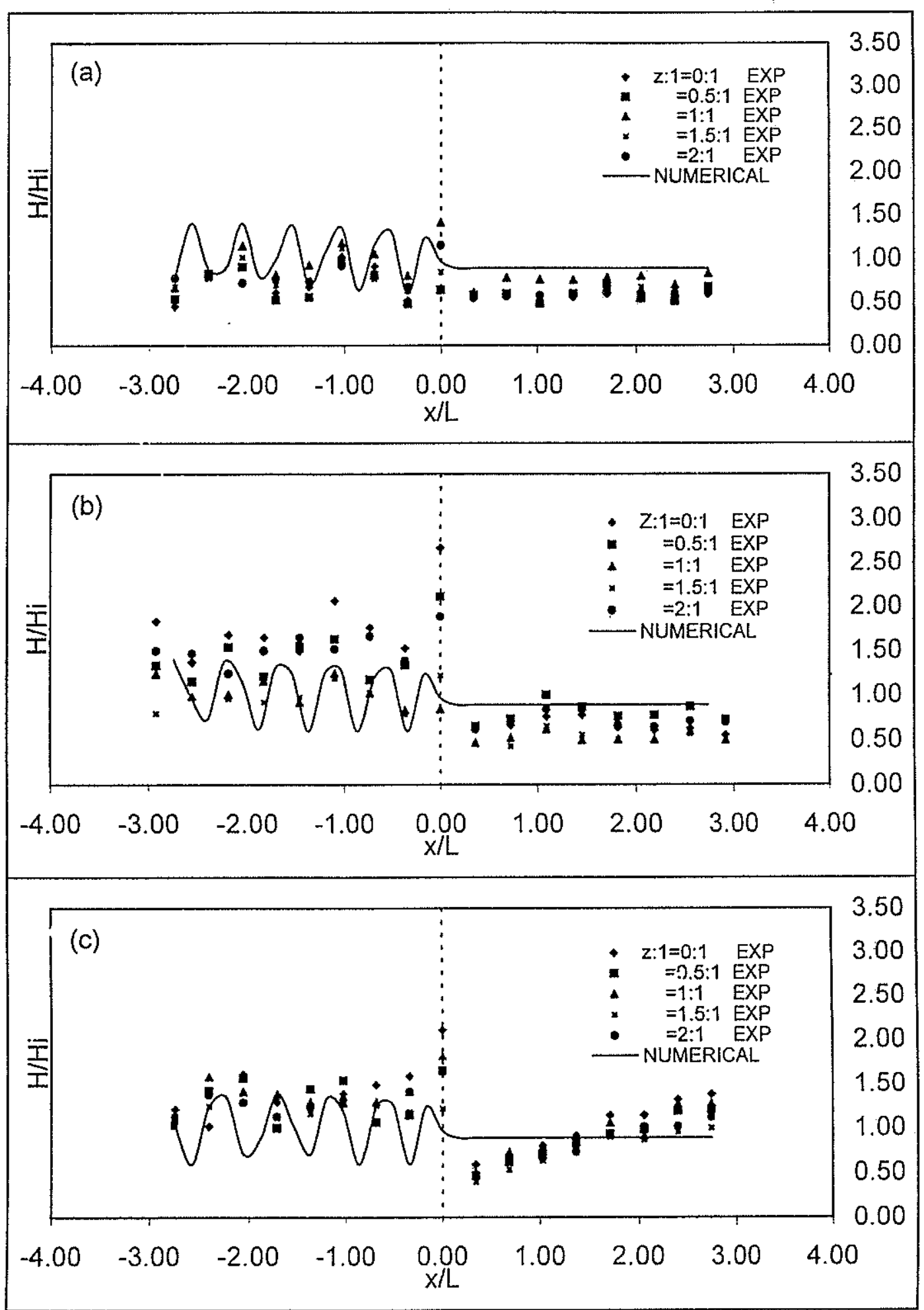

Fig. (4) The Comparison Between Numerical and Experimental Results for the Effect of the Breakwater Side Slope and the Relative Wave Height Distribution When kh tanh $(\mathrm{kh})=0.61$ And $\mathrm{D} / \mathrm{h}=0.75$ For:
(a) $\mathrm{s}=0 \%$
(b) $s=1 \%$
(c) $s=2 \%$ 


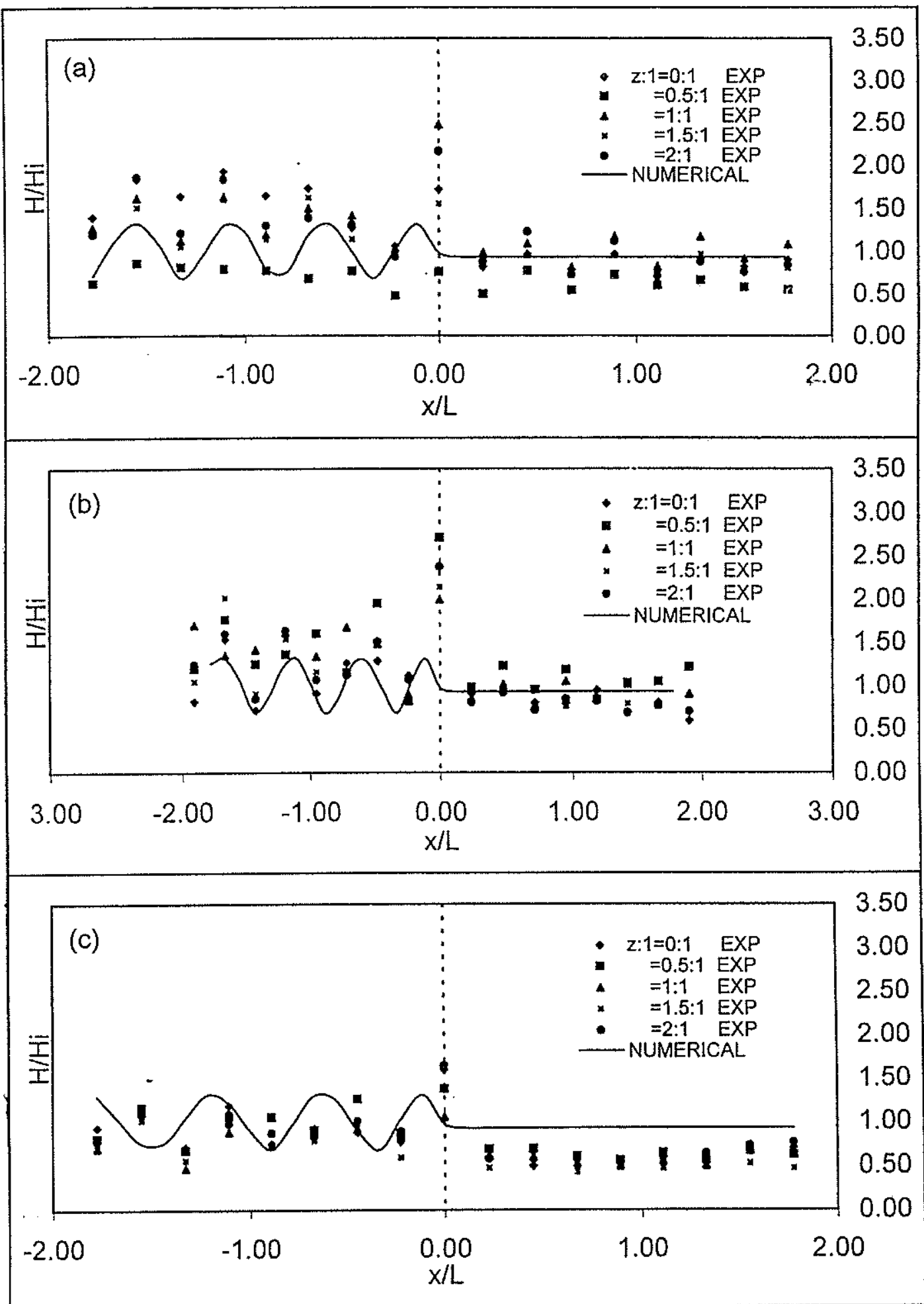

Fig. (5) The Comparison Between Numerical and Experimental Results for the Effect of the Breakwater Side Slope and the Relative Wave Height Distribution When kh tanh $(k h)=0.29$ And $D / h=0.75$ For:
(a) $\mathrm{s}=0 \%$
(b) $s=1 \%$
(c) $s=2 \%$ 


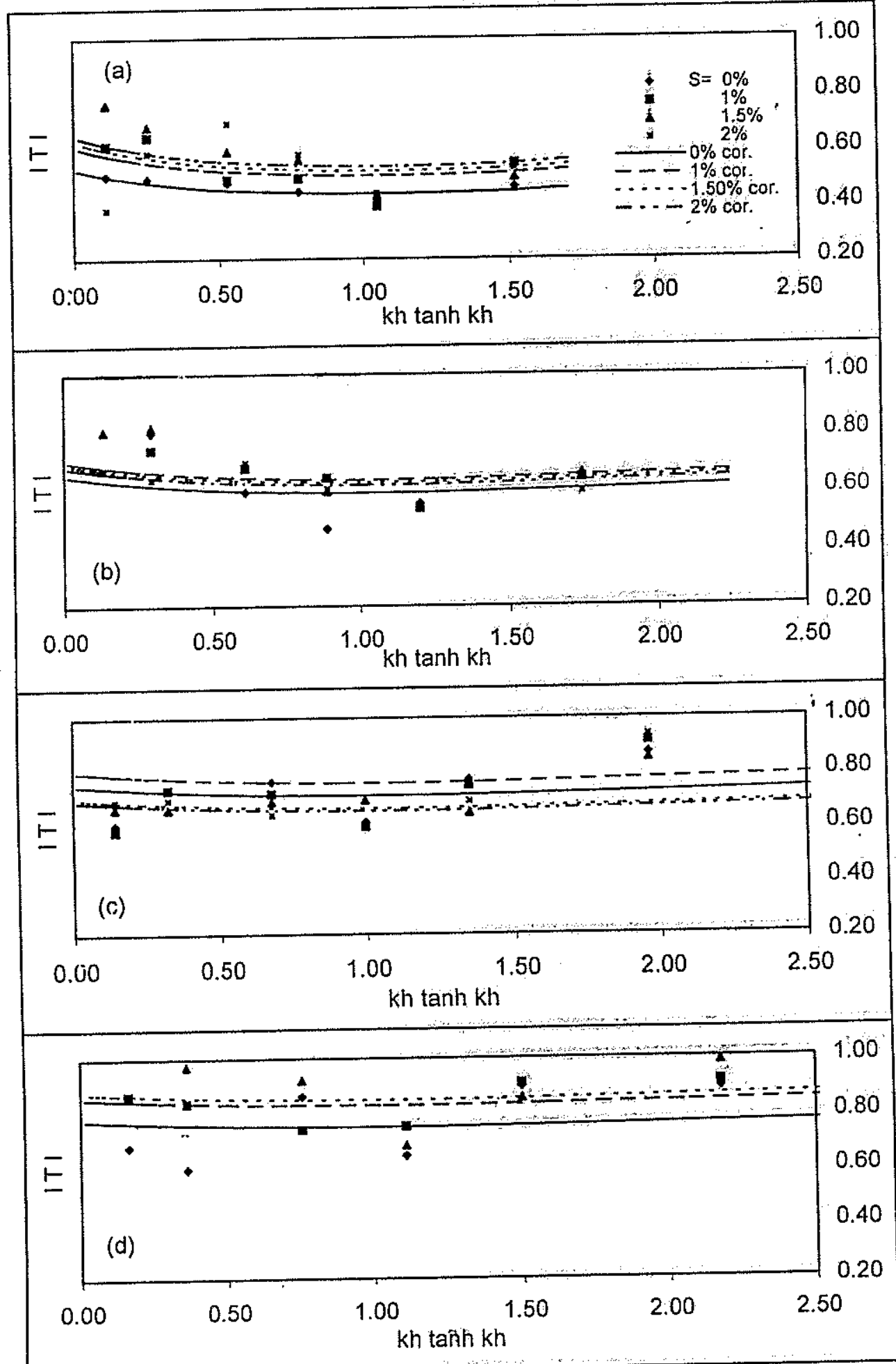

Fig. (6) The Comparison Between the Experimental Results and the Adjusted Numerical Results for Transmission Coefficient When the Breakwater Side Slope is 2:1 :
(a) $D / h=0.86$
(b) $D / h=0.75$
(c) $D / h=0.67$
(d) $\mathrm{D} / \mathrm{h}=0.60$ 


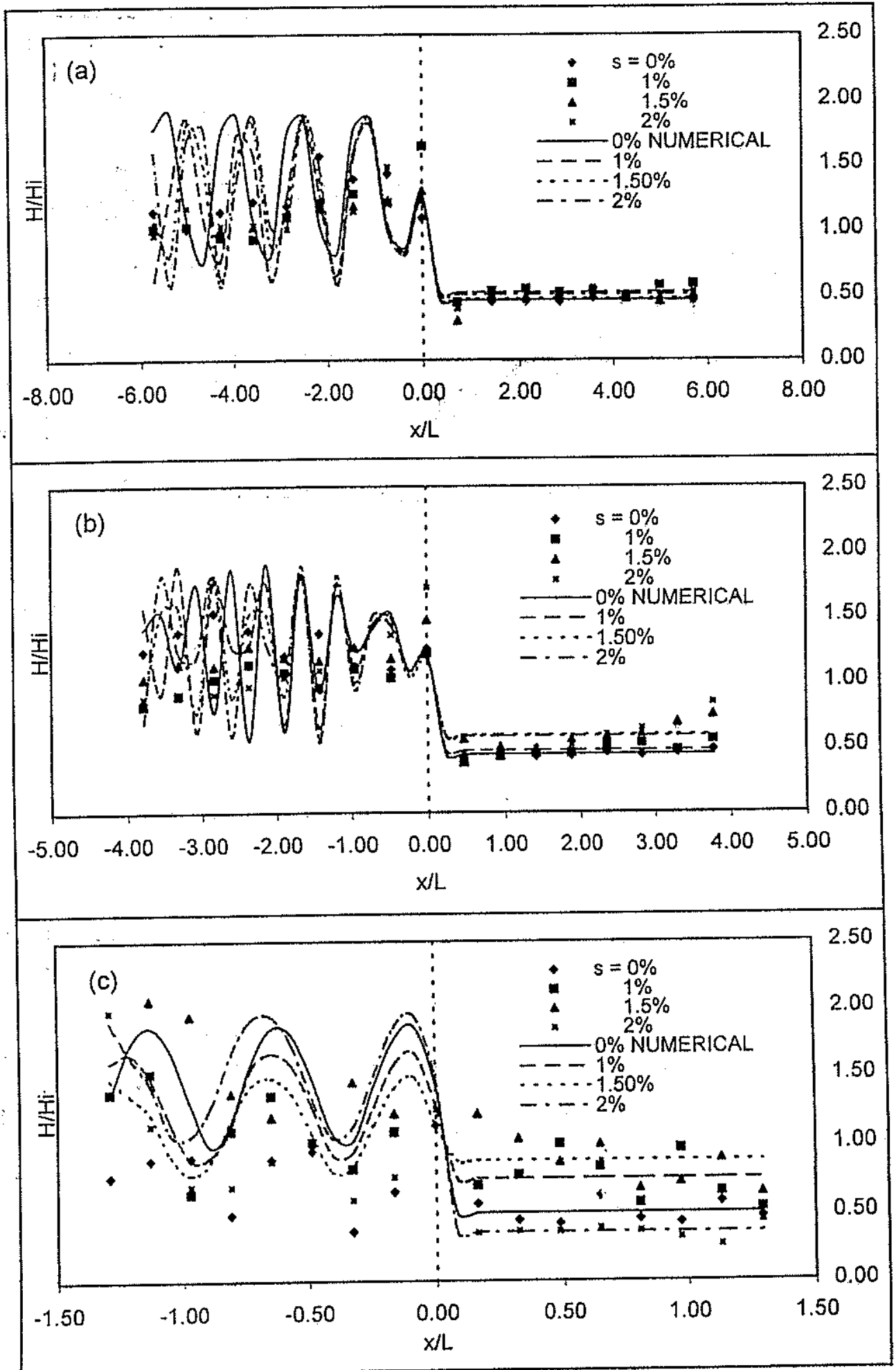

Fig. (7) The Comparison Between the Experimental Results and the Adjusted Numerical Results for Relative Wave Height Distribution When the Breakwater Side Slope is 2:1:
(a) kh tanh $\mathrm{kh}=1.52$
(b) $\mathrm{kh} \tanh \mathrm{kh}=0.78$
(c) $\mathrm{kh} \tanh \mathrm{kh}=0.11$ 
intermediate waves as shown in figure (4).

\section{RESULTS ANALYSIS:}

The numerical results become nearly from experimental results as the breakwater sids slope becomes steeper. This means the experimental results obtained from the breakwater of sile slope of 0:1 gives the nearest value from the numerical results. This is duo to the numerical model is considered vertical submerged barrier with small thickness. The numerical model is well estimated the wave field around the submerged breakwater as well as the relative breakwater height decreases.

The experimental result analysis, Heikal et al (2002), the breakwater side slope of 2:1 gives the smallest transmitted waves. To adjust the numerical model to determine the transmission coefficient accurately, the correction factor $\mathrm{Cc}$ must be taken into consideration as follows:

$$
\mathrm{T}=\mathrm{c}_{\mathrm{c}} \mathrm{T}_{\mathrm{n}}
$$

Where: $\mathrm{Cc}_{\mathrm{c}}$ is the correction factor as the following table:

Table (1) The Correction Factor $(\mathrm{cc})$ For Side Slope 2:1.

\begin{tabular}{|c|c|c|c|c|}
\hline \multirow{2}{*}{$\mathrm{D} / \mathrm{h}$} & \multicolumn{4}{|c|}{$\mathrm{S}$} \\
\cline { 2 - 5 } & $0 \%$ & $1 \%$ & $1.5 \%$ & $2 \%$ \\
\hline 0.86 & 0.53 & 0.61 & 0.63 & 0.65 \\
\hline 0.75 & 0.65 & 0.70 & 0.69 & 0.68 \\
\hline 0.67 & 0.75 & 0.80 & 0.70 & 0.69 \\
\hline 0.60 & 0.78 & 0.86 & 0.88 & \multicolumn{1}{|c}{} \\
\hline
\end{tabular}

Figures (6) and (7) present the comparison between the adjusted numerical results with the experimental results for the best breakwater side slope $(2: 1)$ for different relative frequencies, relative hreakwater heights and beach slopes. Figure (6) presents the comparison for the transmission coefficients for different relative breakwater heights and beach slopes. Figure (7) presents the comparison for the relative wave height distribution for different relative wave frequencies and licki: slopes when the relative breakwater height is 0.86 . The numerical relative wave heights shoreward are adjusted by the correction factor $c_{c}$. The relation between the reflection and Iransmission coefficients can adjust the numerical relative wave height seaward as follows:

$$
\mathrm{R}^{\prime}=\sqrt{1-\mathrm{T}^{\prime 2}}
$$

where $R^{\prime}$ and $T^{\prime}$ are the adjusted reflection and transmission coefficients respectively. 


\section{CONCLUSIONS:}

The summaries of conclusions are:

1. The proposed numerical model gives a good estimation for the transmitted waves for vertical and nearly vertical breakwaters for different wave characteristics and beach slopes.

2. The proposed numerical model was adjusted for the effective breakwater side slope $(2: 1)$ by using a suitable calibration coefficient.

3. The numerical model is well estimated the wave field around the submerged breakwater as well as the relative breakwater height decreases.

\section{REFERENCES:}

1. Abdul Khader, M.H. and Rai, S.P.(1980) "A Study of Submerged

Breakwaters" J. of Hydraulic

Research 18 No. 2.

2. Abul-Azm A.G. (1993) "Wave Diffraction Through Submerged Breakwaters" JWWPOE, Vol. 119, No. 6.

3. Dick, T.M. and Brebrier, A.

(1968) "Solid and Permeable Submerged Breakwaters" Proc. 11.th. Conf. On Coastal Engineering, ASCE, New York, N.Y., II, 1141-1158.

4. Garrison, C.J. and Rao, V.S. (1971) "Interaction of Waves With Submerged Objects" 3J. of WWPCOE,ASCE,Vol.98.

5. Heikal, E.M, Ibraheem, A. A., Owais, T.M. and Koraim, A.S.
(2002) "Damping Action Of near Shore Trapezoidal Submerged Breakwaters' Scientific Bulletin, Eng. Faculty, Ain Shams University, (Under Publication).

6. Heikal, E. M. and Attar, A. A. (1997) "Effect Of Beach Slope On The Efficiency Of Submerged Breakwaters" $2^{\text {nd }}$. Intr. Conf., Mansoura Univ., pp273-283.

7. Heikal, E. M. (1997) "The Validity of Linear Wave Theory in The Determination Of The Efficiency Of Submerged Breakwaters On Sloped Beaches" EJEST J. Zagazig Univ., Vol. 1, No. 2, pp26-30.

8. Heikal, E. M. (1997) "Shore Protection By Submerged Flexible Breakwaters" EJEST J. Zagazig Univ., Vol. 1, No. 1, pp17.

9. Johnson, J.W., Fuches, R.A. and Morison, J. R. (1951) "The Damping Action Of Submerged Breakwaters" Trans. Amer. Geoph. Union, 32(5), 704718.OE, ASCE, Vol.98.

10. Kobayashi, N., and Watson, K. D. (1987). "Wave reflection and run up on smooth slopes." Proc., Coast. Hydrodynamics, ASCE, 548-563.

11. Kobayashi, N., and Wurjanto, A. (1989). "Wave transmission over submerged breakwaters." J. Waterway, Port, Coastal and Ocean Eng., ASCE, Vol. 115, No. $5,662-680$. 